\section{Dissemination and persistence of Pseudomonas spp. in small-scale dairy farms}

Daniele Michele Nucera, ${ }^{1}$

Sara Lomonaco, ${ }^{2}$ Patrizia Morra, ${ }^{2}$

Marco Francesco Ortoffi, ${ }^{2}$

Daniele Giaccone, ${ }^{3}$ Maria Ausilia Grassi ${ }^{2}$

'Department of Agricultural, Forest and

Food Sciences, University of Turin,

Grugliasco (TO); ' 2 Department of

Veterinary Sciences, University of Turin,

Grugliasco (TO); ${ }^{3}$ Regional Association of

Farmers of Piedmont, Turin, Italy

\section{Abstract}

This study was aimed at collecting data on presence, dissemination and persistence of Pseudomonas in small-scale dairy farms. Six farms (located in Piedmont) were visited three times over 2014: 116 waters (wells and different faucets/pipes) and 117 environmental samples (milking equipments and drains) were collected. Enumeration of Pseudomonadaceae was performed, 3-5 colonies/samples were selected for identification via 16 SrDNA/oprI polymerase chain reaction (PCR), and typed by enterobacterial-repetitive-intergenic-consensus (ERIC)-PCR. Pseudomonadaceae were detected in $77 \%$ of samples. No statistical differences were found among proportions of positives across farms, sample typologies and seasons. Most isolates were Pseudomonas fluorescens (45\%), and ERIC-PCR showed 32 persistent types diffused across farms. All in all, Pseudomonas spp. represents a challenge, considering its presence over time in water as well as in teat cups, indicating a continuous source of contamination. Moreover, persistency of strains may indicate biofilm-formation and/or sanitisers resistance, therefore emphasising the role of primary production for preventing milk contamination by Pseudomonas spp.

\section{Introduction}

Psychrotolerant bacteria are mainly ubiquitous organisms able to grow at refrigeration temperatures regardless of their optimal growth temperature (Morita, 1975). Pseudomoadaceae represent a problem in primary production as well as in dairy-transforming plant: they may cause mastitis (Daly et al., 1999) and milk/dairy products alterations even if these are kept under strict refrigeration temperatures (Ternström et al., 1993). As contam- inants of cheeses, Pseudomonas spp. can induce serious defects such as changes in colour of cheese surfaces (Leriche et al., 2004; Martin et al., 2011). In heat-treated milk, even in ultra high temperature milk, alterations due to Pseudomonas spp. enzymes are still possible, and these include gelation (Datta and Deeth, 2001). Some polymerase chain reaction (PCR) based methods have been applied for Pseudomonas spp. typing in order to detect genetic diversity and assess putative sources of contamination in dairy production, and methods were applied successfully (Eneroth $e t$ al., 2000; Leriche et al., 2004; Marchand et al., 2009), identifying also persistent strains responsible for recurrent contamination. However, considering that Pseudomonas spp. may contaminate raw milk via biofilms in the milk tanks, contaminated water, or soil, few studies have been conducted focusing on primary production. For example, some authors (Leriche and Fayolle, 2012) revealed the presence and the level of Pseudomonas spp. and related species in milk just after milking and identified hygienic programmes and water quality as the most influential control measures. For this reason, the aim of this study was to collect new data on the presence of Pseudomonadaceae in milk producing farms, assess seasonal variation in frequency of contamination, and verify, through PCR-typing, the presence of persistent and largely diffused strains in a well defined food-production chain located entirely in Piedmont.

\section{Materials and Methods}

For this study it was selected a set of 6 farms producing milk for a large-scale production plant located in Piedmont. Farms were selected because of the presence and use of waters from underground wells: four of them were selected considering milk production and management procedures (representative of regional production: less than 100 milking cows, family owned and with few operators); two farms were selected because characterised by a similar production profile but also by having a small scale dairy production plant annexed.

Each farm was visited three times over 2014; during each visit water (from wells and different faucets/pipes) and environmental samples were collected. Samples of water were aseptically collected using $500 \mathrm{~mL}$ sterile bottles (intended for laboratory use) and placed at refrigeration temperature until analysis, few hours after collection. Environmental samples were collected from teat cups and from drains. The former, by scrubbing one sponge on the four cups of the same milking machine unit, whereas the latter by scrubbing an area of 100 $\mathrm{cm}^{2}$ of drains located in the bulk-tank room
Correspondence: Daniele Michele Nucera, Department of Agricultural, Forest and Food Sciences, University of Turin, Largo Braccini 2, 10095 Grugliasco (T0), Italy.

Tel: +39.011.6708565 - Fax: +39.011 .6708566 .

E-mail:daniele.nucera@unito.it

Key words: Pseudomonas; Small-scale dairy farms; Water; Typing; Persistence.

Contributions: all the authors contributed equally in data collection, analysis and manuscript preparation.

Conflict of interest: the authors declare no potential conflict of interest.

Funding: Piedmont Region: Measure 124, Action 1 (Cooperation for the development of new products, processes and technologies in the agri-food sector-challenges; Health Check).

Received for publication: 29 November 2016.

Revision received: 8 February 2016.

Accepted for publication: 8 February 2016.

This work is licensed under a Creative Commons Attribution-NonCommercial 4.0 International License (CC BY-NC 4.0).

(C) Copyright D.M. Nucera et al., 2016

Licensee PAGEPress, Italy

Italian Journal of Food Safety 2016; 5:5652

doi:10.4081/ijfs.2016.5652

and in the two annexed dairy plants. Sponge bags were stored at refrigeration temperature and analyzed the same day of collection.

Enumeration of Pseudomonadaceae was performed using Cetrimide-Nalidixic Acid Psudomonas agar, with previous membrane filtration $(250 \mathrm{~mL})$ for water samples. After incubation and enumeration, from 3 to 5 colonies/samples were selected for identification. Selection was applied to the highest dilution plated and when more than 10 colonies were present, 5 were used for further analyses. If less than ten colonies were present the number of selected ones was reduced to three. Selected colonies were identified via 16SrDNA/oprI PCR (De Vos et al., 1997) and then sequenced. For identification, chromatograms were then retrieved, corrected (if needed) and compared through Blast-N similarity search (Genbank) with worldwide dataset.

After identification, each colony was cultured in Brian Hearth Infusion Broth and 1.8 mL used for DNA extraction with Ultra Clean Microbial DNA Extraction kit. The DNA was challenged with enterobacterial-repetitiveintergenic-consensus (ERIC) PCR, following the published protocol (Nucera et al., 2013). After staining, profiles were visualised using a GelDoc UV transilluminator. These were first 
checked by visual inspection, and then a software-assisted analysis was performed (Bionumerics ${ }^{\circledR}$; Applied Maths NV, SintMartens-Latem, Belgium). Fingerprint comparison was carried out using Dice coefficient and unweighted pair group method with arithmetic mean algorithm. To set the threshold similarity level for indistinguishable patterns, a repeatability assay was performed by triplicate analyses (Corich et al., 2005) on five strains. The lowest similarity level observed within each sample was used to define identical genotypes, minimising the intra-sample variation (Ravelo et al., 2003).

Differences between proportion of positive samples of Pseudomonas spp. across time points was performed using chi-square tests, performed in SPSS $^{\circledR}$ (v. 11.0). A proportion was calculated as the number of positive samples at each time point/number of total samples collected. The same test was also used to evidence differences across farms. In this latter case the proportions were calculated by dividing the number of positive samples in each farm by the total number of samples collected in each farm. Results were considered significant when $\mathrm{P}<0.05$.

\section{Results and Discussion}

Results showed that out of 233 samples retrieved ( 85 from teat cups, 32 from drains, and 116 from water pipes/faucets), 180 (77.3\%) were positive for Pseudomonadaceae. They also showed that the proportion of positive samples was 73 and $75 \%$ for teat cups and drains, respectively; in samples of water the frequency of positive samples ranged from $86 \%$ in water collected from underground wells, to $73 \%$ in water used for milk processing (in annexed dairy plant); water collected from milking room and tank room showed both positive plates in $82 \%$ of the samples analyzed. Statistical analyses showed that there was no statistical difference among proportion of positive across sample types (Chi-square $=0.15$; $\mathrm{P}=0.99$ ). Considering that sampling was performed in three different occasions, a comparison between frequency of positive samples per sampling visit for each sample type was also performed (Table 1).

Considering that there was no difference per visit nor per sample typology all sample were grouped together and the frequency of positive samples per farm was calculated. The comparison between farms based on this variable was not significant (Table 2).

Polymerase chain reaction confirmed the presence of Pseudomonas fluorescent (45\% of the isolates) as the predominant species in dairy environment, as previously reported by other authors (Wang and Jayarao, 2001; Dogan and Boor, 2004). However, typing results with ERIC PCR evidenced a genetic heterogeneity among the 250 tested strains (derived from 180 samples), all of which were similar at the $10 \%$ similarity level. A genetic heterogeneity was already observed within Pseudomonas species by other authors even if using different typing methods (Wang and Jayarao, 2001; Dogan and Boor, 2004). Considering the grouping of the PCR patterns, 18 clusters (group of strains with $80 \%$ or greater similarity) and 3 outliers were generated. There were 32 PCR profiles shared between strains collected in different time points from either the same or different farms in various sample types (Table 3 ).

These results show that 14 profiles were persistent over a period of 8 or more months and that 27 were shared between more than 2 farms, with three (P3, P10, and P14) being present in 4 of the 6 sampled dairies. Finally,

Table 1. Proportion of positive samples in different sample typologies considering the different sampling times.

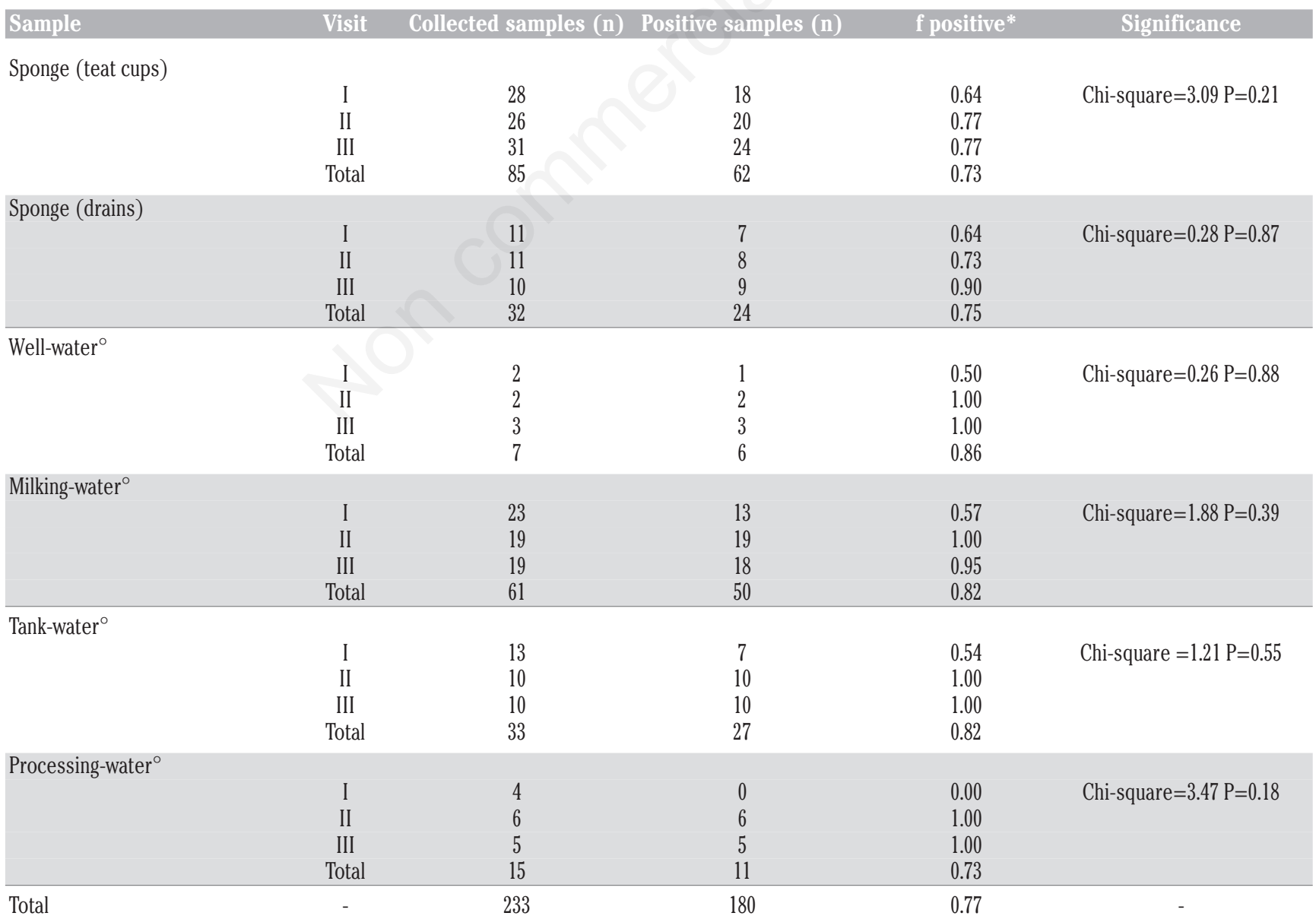

I, winter/spring; II, summer; III, fall. *Number of positive samples per visit, regardless of the number of selected colonies; ${ }^{\circ}$ water collected from different faucets/pipes located within the same room. 
only 8 of the 32 persistent profiles were retrieved from only one sample typology, the remaining being present in two $(\mathrm{N}=17)$ or three $(\mathrm{N}=7)$ sample types.

All in all, these results highlight that the frequency of Pseudomonadaceae in dairy farm is high in all sample typologies, however no difference among proportions was observed among farms and seasons, therefore implying a constant environmental contamination. Considering that water is one of the most acknowledged sources of these family of Gram negative bacteria (Leriche et al., 2004; Leriche and Fayolle, 2012) our results confirmed that Pseudomonas spp. is present in water used in primary production, both in well waters and in potable water, as already suggested (Leriche and Fayolle, 2012). The high frequency of positive in drains and in teat coups indicates that microbes are still present and alive after the sanitising procedures as well. In fact, specimens were all collected just after the washing cycle of the milking machine was concluded.
Our results seem to confirm what reported in the literature (Leriche and Fayolle, 2012). The presence of recurrent contamination suggests two possible scenarios: i) water may act as the primary vehicle of contamination in cleaned equipment, or ii) sanitising procedures are not effective in neutralising Pseudomonas spp. In our study no seasonal difference was observed in Pseudomonadaceae similarly to what observed by other researcher (Leriche and Fayolle, 2012). However, the lack of statistical significant differences across seasons for drains, well waters, processing waters and tank room waters may also be related to the low number of samples tested for each visit. This result may thus indicate that the contamination is diffused in primary production and no protective seasonal effect exists. However, in order to investigate this hypothesis a larger number of samples would need to be collected for each sample type and in each season.

Considering results of the typing PCR, even if the population examined showed great het- erogeneity, 32 profiles were shared between strains collected in different farms or from different sample types (Table 3). These observations imply the presence of highly diffused genetic types, which may be spread within a well-defined geographic region, indicating that putative routes of transmission may exist in different environments. Among these, operators, equipments, milk transporting trucks, and water may represent the putative sources.

The presence of the same PCR type in different sample typologies within the same farm, indicates that, once the microbes are present, they can disseminate in all the dairy environments: from the barn to the milking room, from milking room, to tank room, and from this latter to the annexed dairy production plants. Profiles P14, P16, P18, P20, P23 e P32 were all present in primary production and in the annexed dairy transforming plants.

Another interesting result is the presence of PCR types that persist for periods lasting from 2 to 10 months. Persistent contamination was

Table 2. Proportion of positive samples in the six sampled farms.

\begin{tabular}{lcccc} 
Farm & Collected samples $(\mathrm{n})$ & Positive samples (n) & S positive & Significance \\
$\mathrm{A}$ & 35 & 23 & 0.66 & 0.74 \\
$\mathrm{~B}$ & 43 & 32 & 0.77 \\
$\mathrm{C}$ & 52 & 40 & 0.79 \\
$\mathrm{D}$ & 34 & 27 & 1.00 & 0.77 \\
$\mathrm{E}$ & 21 & 21 & 0.77 & - \\
$\mathrm{F}$ & 48 & 37 & 180 & Chuare=1.11 P=0.71 \\
\hline Total & 233 & & & \\
\hline
\end{tabular}

Table 3. List of persistent profiles with relative persistence, sources and number of farms from which the strains were isolated.

\begin{tabular}{lccc}
\hline PCR profile & Persistency (months) & Sources & Number of farms \\
P1, P2, P13 & 4 & Water, teat cups & 2 \\
\hline P3, P7 & 8 & Teat cups, drains & (P3), $2(\mathrm{P} 7)$ \\
P4, P5 & $4(\mathrm{P} 4), 2(\mathrm{P} 5)$ & Teat cups & 2 \\
P6 & 6 & Drains & 3 \\
P8, P10, P31 & 10 & Teat cups, drains & $2(\mathrm{P} 8$, P31), $4(\mathrm{P} 10)$ \\
\hline P9, P16, P32 & $5(\mathrm{P} 9, \mathrm{P} 16), 2(\mathrm{P} 32)$ & Teat cups, drains & 2 \\
P11 & 9 & Water, teat cups & 2 \\
P12 & 9 & Drains & 2 \\
P14, P30 & 6 & Teat cups, drains & $4(\mathrm{P} 14), 2(\mathrm{P} 30)$ \\
\hline P15 & 10 & Water, teat cups, drains & 1 \\
P17, P21 & 9 & Teat cups & $1(\mathrm{P} 17), 2(\mathrm{P} 21)$ \\
P18 & 9 & Teat cups, drains & 3 \\
P19, P20 & $2(\mathrm{P} 19), 10(\mathrm{P} 20)$ & Teat cups, water & 2 \\
\hline P22, P23 & 8 & Teat cups, water, drains & 2 \\
P24 & 3 & Teat cups, water, drains & 3 \\
\hline P25 & 10 & Teat cups, water, drains & 2 \\
P26, P27 & 7 & Teat cups, water, drains & 3 \\
\hline P28, P29 & 4 & Water & 1 \\
\hline
\end{tabular}

PCR, polymerase chain reaction. 
also recorded previously (Eneroth et al., 2000), showing a strain persisting in a dairy plant for 15 months. The persistence observed in the present research may be due to multiple reasons: i) the sanitation procedures are not effective (use of ineffective dose/contact time) (Leriche and Fayolle, 2012); ii) development of resistance to biocides (DeQueiroz and Day, 2007; Shen et al., 2012); or iii) production of biofilms (Holm et al., 2004; The et al., 2014). Hence, future studies on typed strains are needed in order to investigate their susceptibility to sanitisers used in the selected farms, as well as in vitro studies for assessing the ability of persistence strains to form biofilm, using coupons made of different materials.

\section{Conclusions}

In conclusion, given that European Regulation set hygiene criteria for milk in primary production without including Pseudomonas spp. (which is not routinely detected, which is the reason why its presence is largely underestimated), this research highlighted that Pseudomonadaceae are extremely diffused in farm environments and water sources. Considering that this family of bacteria is well known for pigment production in dairies, it appears important the need of the elaboration of control programmes, by means of implementation of good hygienic practices manuals, particularly for small scale farms.

\section{References}

Corich V, Mattiazzi C, Soldati E, Carraro A, Giacomini A, 2005. Sau-PCR, a novel amplification technique for genetic fingerprinting of microorganisms. Appl Environ Microb 71:6401-6.

Daly M, Power E, Björkroth J, Sheehan P,
O'Connell A, Colgan M, Korkeala H, Fanning F, 1999. Molecular analysis of Psuodomonas aeruginosa: epidemiological investigation of mastitis outbreaks in Irish dairy herds. Appl Environ Microb 65:2723-9.

Datta N, Deeth HC, 2001. Age gelation of UHTmilk: a review. Food Bioprod Process 79:197210.

DeQueiroz GA, Day DF, 2007. Antimicrobial activity and effectiveness of a combination of sodium hypochlorite and hydrogen peroxide in killing and removing Pseudomonas aeruginosa biofilms from surfaces. J Appl Microbiol 103:794-802.

De Vos D, Lim A, Pirnay JP, Struelens M, Vandenvelde C, Duinslaeger L, Vanderkelen A, Cornelis P, 1997. Direct detection and identification of Pseudomonas aeruginosa in clinical samples such as skin biopsy specimens and expectorations by multiplex PCR based on two outer membrane lipoprotein genes, oprI and oprL. J Clin Microbiol 35:1295-9.

Dogan B, Boor KJ, 2004. Genetic diversity and spoilage potentials among Pseudomonas spp. isolated from fluid milk products and dairy processing plants. Appl Environ Microb 69:130-8.

Eneroth A, Ahrneh S, Molin G, 2000. Contamination routes of Gram-negative spoilage bacteria in the production of pasteurised milk, evaluated by randomly amplified polymorphic DNA (RAPD). Int Dairy J 10:325-31.

Holm C, Jepsen L, Larsen M, Jespersen L, 2004. Predominant microflora of downgraded danish bulk tank milk. J Dairy Sci 87:1151-7.

Leriche F, Bordessoules A, Fayolle K, Karoui R, Laval K, Leblanc L, Dufour E, 2004. Alteration of raw-milk cheese by Pseudomonas spp.: monitoring the sources of contamination using fluorescence spectroscopy and metabolic profiling. J Microbiol Meth 59:33-41.

Leriche F, Fayolle K, 2012. No seasonal effect on culturable pseudomonads in fresh milks from cattle herds. J Dairy Sci 95:2299-306.
Marchand S, Heylen K, Messens W, Coudijzer K, De Vos P, Dewettinck K, Herman L, De Block J, Heyndrickx M, 2009. Seasonal influence on heat-resistant proteolytic capacity of Pseudomonas lundensis and Pseudomonas fragi, predominant milk spoilers isolated from Belgian raw milk samples. Environ Microbiol 11:467-82.

Martin NH, Murphy SC, Ralyea RD, Wiedmann M, Boor KJ, 2011. When cheese gets the blues: Pseudomonas fluorescens as the causative agent of cheese spoilage. J Dairy Sci 4:3176-83.

Morita RY, 1975. Psychrophilic bacteria. Bacteriol Rev 39:146-67.

Nucera DM, Lomonaco S, Costa A, Morra P, Grassi MA, 2013. Diagnostic performance of rep-PCR as a rapid subtyping method for Listeria monocytogenes. Food Anal Method 6:868-71.

Ravelo C, Magariños B, López-Romalde S, Taranzo AE, Romalde JL, 2003. Molecular fingerprinting of fish-pathogenic Lactococcus garvieae strains by random amplified polymorphic DNA analysis. J Clin Microbiol 41:751-6.

Shen C, Luo Y, Nou X, Bauchan G, Zhou B, Wang Q, Millner P, 2012. Enhanced inactivation of Salmonella and Pseudomonas biofilms on stainless steel by use of T-128, a fresh-produce washing aid, in chlorinated wash solutions. Appl Environ Microb 78:6789-98.

Ternström A, Lindberg AM, Molin G, 1993. Classification of the spoilage flora of raw and pasteurized bovine milk, with special reference to Pseudomonas and Bacillus. J Appl Bacteriol 75:25-34.

The KH, Flint S, Palmer J, Andrewes P, Bremer P, Lindsay D, 2014. Biofilm. An unrecognised source of spoilage enzymes in dairy products? Int Dairy J 34:32-40.

Wang L, Jayarao BM, 2001. Phenotypic and genotypic characterization of Pseudomonas fluorescens isolated from bulk tank milk. J Dairy Sci 84:1421-9. 